\title{
Modelling sliding resistance of tolerably mobile subsea mudmats
}

\author{
X. FENG* and S. GOURVENEC*
}

\begin{abstract}
Subsea infrastructure for deep-water oil and gas developments is often supported by mudmat foundations. Traditionally, subsea mudmats are designed to resist the loads imposed by pipeline thermal expansion and contraction while remaining stationary. As subsea facilities have grown, the required size and weight of the mudmats challenge the handling capacity of installation vessels and raise costs. Tolerable mobility of a subsea mudmat can significantly relieve the applied loads, leading to reduced mudmat size and weight. In this paper, the cyclic shearing and reconsolidation response of fine-grained soil around a tolerably mobile mudmat is investigated through results of finite-element analysis using a critical state soil model. The mudmat was subjected to a simulated lifetime of operation, with many cycles of undrained sliding with intervening consolidation between cycles. The sliding resistance was shown to rise exponentially with cycles and reach the drained limit, accompanied by significant strength gain in the subsoil because of the intervening consolidation between movements. The degree of reconsolidation between slides affects the number of cycles required to mobilise the drained limit. The hardening response for periodic shearing with intervening consolidation is shown to scale from the hardening response for continuous undrained shearing by an amount depending on the degree of intervening consolidation during pipeline operation. Expressions for the rate of hardening of sliding resistance of a tolerably mobile mudmat foundation are proposed in this paper to assist design practice.
\end{abstract}

KEYWORDS: clays; consolidation; footings/foundations; offshore engineering; repeated loading

\section{INTRODUCTION}

Subsea mudmats that support seabed infrastructure for deep-water oil and gas developments are subjected to cycles of operational loading as the attached pipelines undergo periodic thermal expansion and contraction during start-up and shut-down events during the life of the field. Conventionally, subsea mudmats are designed to remain stationary by resisting all of the imposed operational loads. The emerging challenge is that, as operational loading becomes more severe and seabeds become softer, the size and weight of mudmats derived from the traditional design methods (e.g. ISO, 2003; API, 2011) challenge the handling capabilities of many installation vessels and raise project costs. Provision of additional specialised vessels with heavylift capability, on top of a standard pipe-laying vessel, affects the economic margins of a project.

Subsea geotechnical infrastructure may be designed to allow movement. Examples of cases in which mobility is currently accepted include controlled lateral buckling of on-bottom pipelines, trench development of steel catenary risers and the installation of drag-in plate anchors (Randolph et al., 2011). The concept of tolerably mobile subsea mudmats for supporting pipeline infrastructure allows a mudmat to slide on the seabed to accommodate pipeline expansion and contraction rather than resist the full expansion (or contraction) load. A tolerably mobile mudmat is also an alternative to the use of mechanical sliding mechanisms on the subsea structure to absorb expansions. Thus, operational load applied to the mat is relieved, allowing foundation size and weight reductions with potentially

Manuscript received 20 August 2015; revised manuscript accepted 8 January 2016. Published online ahead of print 18 February 2016. Discussion on this paper closes on 1 November 2016, for further details see p. ii.

* Centre for Offshore Foundation Systems, The University of Western Australia, Crawley, Perth, WA, Australia. minimal operations during installation (Cathie et al., 2008; Cocjin et al., 2014, 2015; Deeks et al., 2014).

A tolerably mobile subsea mudmat ideally slides repeatedly and reversibly in response to pipeline expansions and contractions. An analytical framework based on continuous planar shearing with concurrent drainage and consolidation was developed by Randolph et al. (2012) and applied to investigate the evolution of axial sliding resistance associated with pipeline 'walking'. Finite-element (FE) analyses (Yan et al., 2014) extended the analytical framework to account for periodic shearing in which full primary consolidation occurs between pipe movements. Even though these works were focused on pipe-soil interaction, the theory can be used as rational guidance over the design of tolerably mobile mudmats. The potential of these mudmats to support subsea infrastructure has been demonstrated through centrifuge model testing (Cocjin et al., 2014; Stuyts et al., 2015). Methods to address aspects of design for tolerably mobile subsea mudmats have been suggested by Bretelle \& Wallerand (2013), Deeks et al. (2014), Cocjin et al. (2015) and Zhou et al. (2015), although a systematic investigation of the sliding response of a tolerably mobile mudmat has not yet been presented.

This paper provides results from numerical analysis of a mobile mudmat on a normally consolidated fine-grained seabed. Small-strain FE analysis and the critical state soil mechanics (CSSM) model, modified Cam-Clay (MCC), are employed to couple the effects of soil shearing caused by foundation sliding, consolidation and soil strength gain. The evolution of horizontal sliding resistance within the lifetime of a mobile mudmat subjected to cyclic shearing and intervening reconsolidation is systematically investigated and the results are synthesised into expressions defining the rate of hardening to assist design practice. This work translates the study of Randolph et al. (2012) to mudmat foundations, and distils the outcomes into quantitative expressions to support design. 
FINITE-ELEMENT MODEL

All of the calculations were carried out using the Abaqus (v 6.10) program (Dassault Systèmes, 2010).

\section{Model description}

The boundary conditions considered in this study are illustrated schematically in Fig. 1. A rigid, impermeable, surface rectangular mudmat with a breadth-to-length ratio, $B / L=0.5$ was considered. This aspect ratio is common for subsea mudmats and is often governed by the configuration of the opening on a pipe-laying vessel through which the mudmats are lowered to the seabed. The breadth of mat was taken as $B=5 \mathrm{~m}$ for all analyses (common in field applications), but results are presented as normalised quantities such that the actual dimension of the foundation is not relevant.

The interface between the underside of the mudmat and the subsoil was taken to be rough in shear with no detachment permitted (i.e. fully bonded). The mudmat remains in compression throughout the loading cycles such that no tendency for separation is observed. An example of a FE mesh used in this study is shown in Fig. 2. The mesh boundaries extend a distance of $3 B$ from the edges and $3 B$ beneath the mat, with horizontally constrained nodes at the vertical sides, and fully constrained nodes at the base. Pore water flow was permitted across the top free surface of the mesh either side of the mudmat, but not across the mat, or the side or base boundaries of the mesh. Flow across the external vertical sides or base of the mesh was not expected as zones of excess pore water pressure generation were confined close to the mudmat and free surface, remote from the external boundaries.

The mat was modelled as a weightless, rigid body with a load reference point (LRP) located centrally at mudline level. A vertical load representing the self-weight of the structures was applied at the LRP to allow for generation of excess pore pressure and the following consolidation, as described later in the section entitled 'Analysis programme'. Sliding was achieved by horizontal translation of the LRP with zero moment. The soil was represented by first-order fully integrated stress-pore fluid continuum elements.

\section{Soil parameters}

The CSSM model in Abaqus, clay plasticity, was used with model parameters to represent MCC (Roscoe \& Burland, 1968). The implementation of MCC in Abaqus uses a Mises surface in the $\pi$-plane and associated flow by defining the flow stress ratio as unity. The numerical parameters used for the analyses are listed in Table 1. These properties are typical of the kaolin clay used for experimental research at the University of Western Australia (Stewart, 1992). The soil

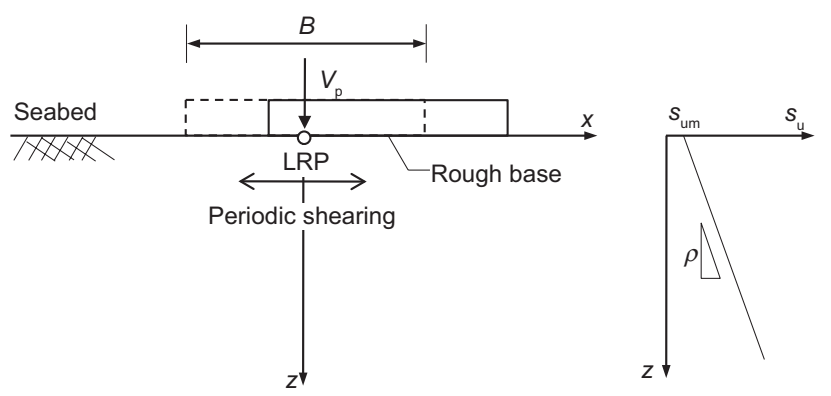

Fig. 1. Schematic diagram of a tolerably mobile mudmat on normally consolidated soil

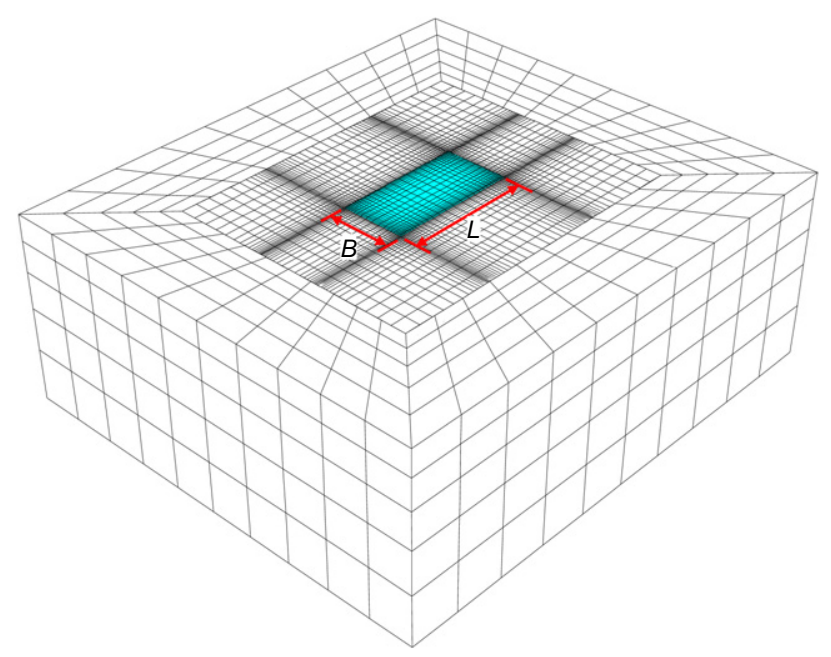

(a)

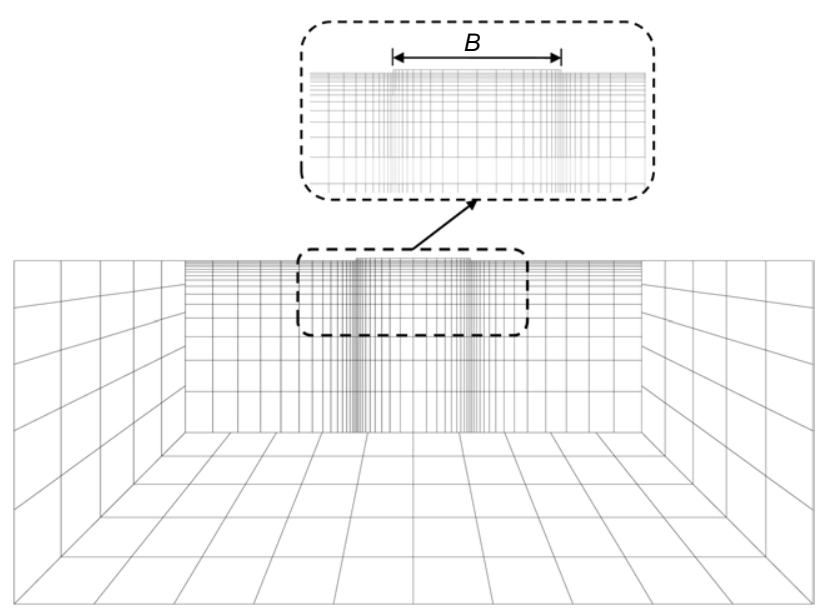

(b)

Fig. 2. Finite-element mesh for tolerably mobile mudmat: (a) isotropic view; (b) elevation view through the mid-point central plane

was considered to be $K_{0}$-consolidated, with $K_{0}=1-\sin \phi_{\mathrm{tc}}^{\prime}$, where $\phi_{\mathrm{tc}}^{\prime}$ is the friction angle for triaxial compression conditions.

A uniform surcharge, $\sigma_{\mathrm{vo}}$, was applied at the upper soil surface (including across the weightless mudmat) to provide a nominal, non-zero value of shear strength at the mudline. The undrained shear strength profile was determined from the MCC input parameters using the expression proposed by Potts \& Zdravkovic (1999).

$$
\frac{s_{\mathrm{u}}}{\sigma_{\mathrm{v}}^{\prime}}=\boldsymbol{g}(\Theta) \cos \Theta \frac{1+2 K_{0}}{3}\left(\frac{1+a^{2}}{2}\right)^{1-(\kappa / \lambda)}
$$

where

$$
\begin{aligned}
& \boldsymbol{g}(\Theta)=\frac{\sin \phi_{\mathrm{cs}}^{\prime}}{\cos \Theta+(1 / \sqrt{3}) \sin \phi_{\mathrm{cs}}^{\prime} \sin \Theta} \\
& a=\frac{\sqrt{3}\left(1-K_{0}\right)}{\boldsymbol{g}\left(-30^{\circ}\right)\left(1+2 K_{0}\right)}
\end{aligned}
$$

where $\Theta$ is the Lode's angle, taken as 0 to represent plane strain shear strength, and $\phi_{\mathrm{cs}}^{\prime}$ is the critical state angle of shearing resistance, $g\left(-30^{\circ}\right)$ is the value of $g(\Theta)$ for the triaxial compression condition, that is, $\Theta=-30^{\circ}$. The derived in situ soil properties are summarised in Table 2. 


\section{Analysis programme}

Initially, the time-settlement response of the mudmat under self-weight loading was investigated and described by a continuous function to provide a reference for the degree of consolidation in subsequent analyses.

Second, a suite of analyses was carried out to define the sliding response over the undrained-drained transition. Continuous sliding of the mat foundation with concurrent drainage was modelled over a range of sliding velocities to investigate the interaction of slide velocity and cumulative time on the mudmat response. The analyses provide a backbone curve that defines benchmark values for fully undrained and fully drained sliding resistance, and the transition through dimensionless time.

Finally, analyses to mimic the operational mode of tolerably mobile mudmats were carried out. After geostatic conditions were achieved, a vertical load equivalent to the self-weight of the foundation and the supported structure was applied, representing touchdown on the seabed. The range of relative vertical load adopted is representative of field conditions. A period of excess pore pressure dissipation under the self-weight load was modelled to represent the delay between touchdown of the mudmat and pipeline operation. Subsequently, the mudmat was displaced horizontally to replicate forward

Table 1. Soil parameters for numerical studies

\begin{tabular}{l|l}
\hline Parameter input for FE analysis & Values \\
\hline Index and engineering parameters & \\
Saturated bulk unit weight, $\gamma_{\mathrm{sat}}: \mathrm{kN} / \mathrm{m}^{3}$ & $16 \cdot 0$ \\
Permeability of soil, $k: \mathrm{m} / \mathrm{s}$ & $1 \times 10^{-9}$ \\
Unit weight of water, $\gamma_{\mathrm{w}}: \mathrm{kN} / \mathrm{m}^{3}$ & $10 \cdot 0$ \\
Porous elastic parameters & $0 \cdot 044$ \\
Recompression index, $\kappa$ & $0 \cdot 3$ \\
Poisson ratio, $v^{\prime}$ & 0 \\
Tensile limit & $0 \cdot 205$ \\
Clay plasticity parameters & $0 \cdot 92$ \\
Virgin compression index, $\lambda$ & $\left(23 \cdot 5^{\circ}\right)$ \\
Stress ratio at critical state, $M=q / p^{\prime}$ & $1 \cdot 0$ \\
(friction angle in triaxial compression, $\left.\phi_{\mathrm{tc}}^{\prime}\right)$ & $1 \cdot 0$ \\
Wet yield surface size, $\beta$ & $2 \cdot 14$ \\
Flow stress ratio, $K$ & \\
Intercept on critical state line $(\mathrm{CSL}), e_{\mathrm{cs}}\left(\right.$ at $\left.p^{\prime}=1\right)$ & \\
\hline
\end{tabular}

Table 2. In situ soil properties

\begin{tabular}{l|l}
\hline Mudline strength, $s_{\mathrm{um}}: \mathrm{kPa}$ & $1 \cdot 431$ \\
Strength gradient, $\rho: \mathrm{kPa} / \mathrm{m}$ & $1 \cdot 717$ \\
Consolidation coefficient (in situ), $c_{\mathrm{v} 0}: \mathrm{m}^{2} / \mathrm{s}$ & $7 \cdot 16 \times 10^{-9}$ \\
\hline
\end{tabular}

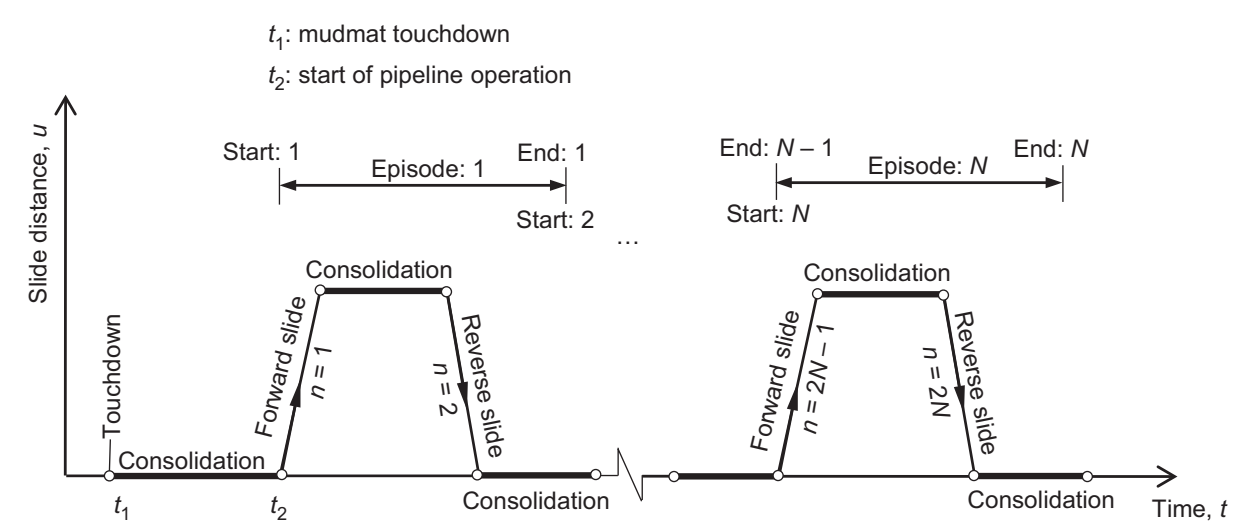

Fig. 3. Schematic diagram of the whole-life response of a mobile mudmat 


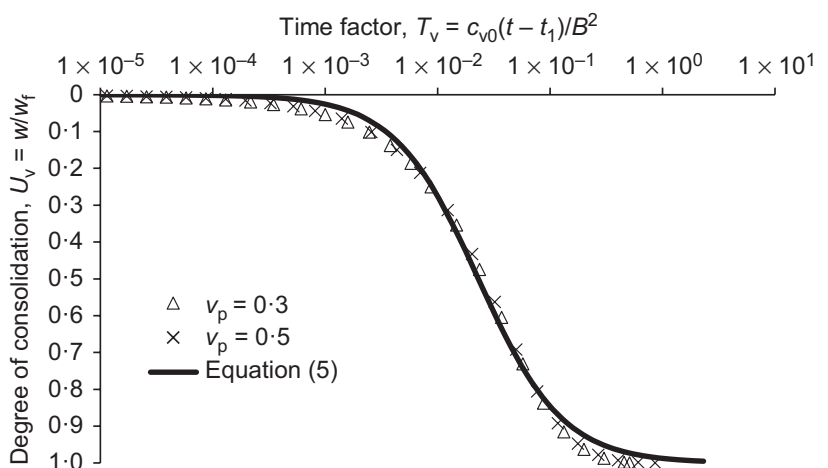

Fig. 4. Normalised time-settlement response of mudmat under varying vertical load mobilisation

installation, and $m_{1}$ is an exponent. $T_{\mathrm{v}, 50}=0.023$ and $m_{1}=1 \cdot 16$ gave the best fit of the FE results.

\section{Undrained-drained continuum for continuous shearing}

The effect of time and slide velocity on the sliding resistance of a subsea mudmat is explored, as analysed by Randolph et al. (2012) for the case of continuous planar shearing. The variation of horizontal sliding resistance with time is represented for different normalised velocities, $v h_{\mathrm{s}} / c_{\mathrm{v} 0}$, where $v$ is the velocity of mudmat sliding, $h_{\mathrm{s}}$ is the thickness of the shear band, here defined as the thickness of the layer of elements beneath the mat $(\approx 1 \% B)$. The thin layer of elements under the foundation was selected so that the sliding resistance could be captured more accurately. If too thick, the sliding resistance would be significantly overestimated because of shearing in a layer of elements of finite thickness rather than across an infinitesimal thickness interface. If too thin, the required initial time increment for stabilisation of the consolidation analyses (Vermeer \& Verruijt, 1981) would become very short. This would require an extremely fast loading rate to achieve the undrained condition in the soil and lead to unwanted oscillation in the model. Normalisation of the slide velocity by the thickness of the first layer of the elements was adopted after the concept proposed by Randolph et al. (2012) in their analytical analysis. For the current FE model, it is impossible to capture the 'real' shear band. An alternative here is to choose the thickness of the first layer of elements underneath the mudmat where the shearing occurred. Therefore, the so-called 'shear band' does not have a physical meaning. The normalised velocity of $v h_{\mathrm{s}} / c_{\mathrm{v} 0}$ is only a scale. It does not matter which dimension is chosen to normalise the velocity, because the mobilised resistance is only determined by the velocity of slide.

The equivalent coefficient of sliding friction, $\mu=H / W^{\prime}$ is shown in Fig. 5 for a range of normalised sliding velocities for the case of $v_{\mathrm{p}}=V_{\mathrm{p}} / V_{\mathrm{uu}}=0.3$ with full primary consolidation following touchdown of the mudmat $\left(U_{\mathrm{v}}=1\right)$. The dimensionless time factor is defined as

$$
T_{\mathrm{h}}=\frac{c_{\mathrm{v} 0}\left(t-t_{2}\right)}{B^{2}}
$$

where $\left(t-t_{2}\right)$ is the elapsed time since the start of the sliding movement.

Separate mobilisation responses for each normalised velocity are intercepted by a common backbone curve. The undrained-drained backbone response provides benchmark values for fully undrained and fully drained sliding resistance, with the latter achieved at a time factor of $T_{\mathrm{h}} \sim 1 \cdot 6$.

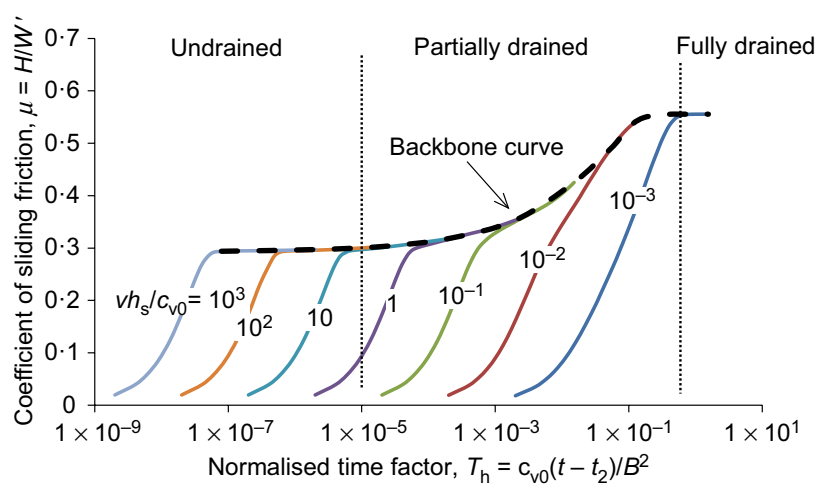

Fig. 5. Monotonic sliding resistance at differing normalised velocities $\left(U_{\mathrm{v}}=1\right)$

The normalised velocities $v h_{\mathrm{s}} / c_{\mathrm{v} 0}=10^{3}$ and $10^{-3}$ lead to responses that show no hardening over the displacement considered, being fully undrained and fully drained, respectively.

The fully undrained sliding resistance following self-weight consolidation after touchdown, $H_{\mathrm{cu}}$, can be predicted using the power function proposed by Feng \& Gourvenec (2015)

$$
H_{\mathrm{cu}}=U_{\mathrm{v}}^{g}\left(H_{\mathrm{cu}, \max }-H_{\mathrm{uu}}^{*}\right)+H_{\mathrm{uu}}^{*}
$$

where $g$ is an exponent, $\sim 0.705$ for the mat geometry under consideration, $H_{\mathrm{uu}}^{*}$ is the unconsolidated, undrained horizontal resistance accounting for the vertical load mobilisation, $v_{\mathrm{p}}$, and it can be determined from the failure envelope for combined vertical and horizontal loading considering self-weight consolidation (Feng \& Gourvenec, 2015). $H_{\text {cu, max }}$ is the maximum consolidated undrained horizontal resistance corresponding to full primary self-weight consolidation.

$$
H_{\mathrm{cu}, \max }=\left(1+R N_{\mathrm{cV}} f_{\sigma} f_{\mathrm{su}} v_{\mathrm{p}}\right) H_{\mathrm{uu}}
$$

where $R$ is the normally consolidated undrained strength ratio, $s_{\mathrm{u}} / \sigma_{\mathrm{v}}^{\prime} ; N_{\mathrm{cv}}$ is the unconsolidated undrained vertical bearing capacity factor; $f_{\sigma}$ is a scaling parameter accounting for the distribution of stress in the zone of soil affected by the operative vertical load; $f_{\text {su }}$ is a scaling parameter to account for interaction of the zone of non-uniform distribution of the increased shear strength and soil involved in the sliding failure mechanism; $v_{\mathrm{p}}$ is the vertical load mobilisation due to mudmat self-weight; and $H_{\mathrm{uu}}$ is the unconsolidated undrained horizontal resistance. For a rectangular surface mudmat on a normally consolidated deposit, the proposed value of $f_{a} f_{\text {su }}$ is 0.919 (Feng \& Gourvenec, 2015). The scaling parameter, $f_{a} f_{\text {su }}$, has been shown to be valid to predict gains in foundation capacity for a range of practical soil properties, being applicable to normally consolidated clay conditions with soil properties other than those considered in this study, as shown in Table 1 (Feng \& Gourvenec, 2015), as well as in over-consolidated conditions (Gourvenec et al., 2014). The equivalent coefficient of sliding friction, $\mu=H / W^{\prime}$ predicted during undrained sliding is 0.292 (Fig. 5), comparable with the defined normally consolidated strength ratio of 0.286 for the soil.

The sliding resistance equals the integral of the mobilised shear stress over the foundation bearing area. For fully drained shearing, the resistance is given by

$$
H_{\mathrm{d}}=\sum_{i=1}^{j} \tau_{z x, i} A_{i}=\mu \sum_{i=1}^{j} \sigma_{z}^{\prime} A_{i}=\mu W^{\prime}
$$

where $j$ is the number of elements across the soil-foundation interface, $A_{i}$ is the contact area of the $i$ th element and $W^{\prime}$ is 


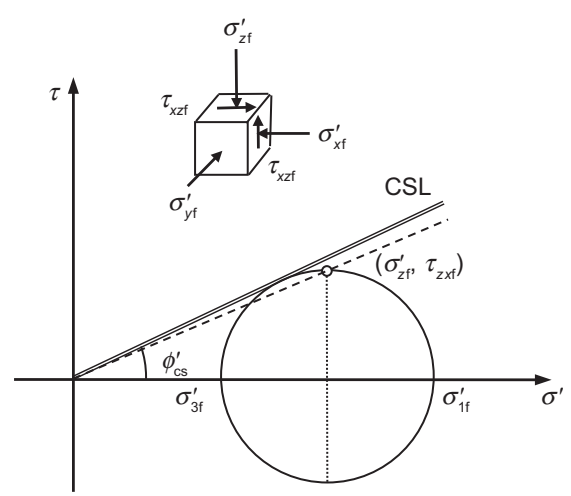

Fig. 6. Stress states at failure for a representative soil element at mudmat invert

the total normal force applied to the soil-foundation interface, $W^{\prime}=V_{\mathrm{p}}+\sigma_{\mathrm{vo}} A$.

The stress states are shown in Fig. 6 for a soil element at the level of the mudmat invert. At failure

$$
\begin{aligned}
& p_{\mathrm{f}}^{\prime}=\sigma_{x \mathrm{f}}^{\prime}=\sigma_{y \mathrm{f}}^{\prime}=\sigma_{z \mathrm{f}}^{\prime} \\
& q_{\mathrm{f}}=\sqrt{3} \tau_{z x \mathrm{f}}
\end{aligned}
$$

The coefficient of friction for drained sliding

$$
\mu=\frac{\tau_{z x \mathrm{f}}}{\sigma_{z \mathrm{f}}^{\prime}}=\frac{q_{\mathrm{f}}}{\sqrt{3} p_{\mathrm{f}}^{\prime}}=\frac{M}{\sqrt{3}}
$$

The coefficient of friction obtained from the FE analysis was approximately 0.555 , over-predicting the theoretical value of 0.532 by $5 \%$ for the soil parameters given in Table 1 . Equation (11) indicates that the coefficient of friction for fully drained sliding is dependent only on one of the MCC parameters, $M$, not the selected surcharge.

The backbone response represents the rate of hardening for undrained continuous shearing without intervening periods of rest, and is a function of the magnitude of the operative vertical load and the degree of self-weight consolidation between mudmat touchdown and pipeline operation. Fig. 7 shows backbone curves for $v_{\mathrm{p}}=0.3$ and $0 \cdot 5$, and for varying degrees of consolidation post touchdown, $U_{\mathrm{v}}$. The backbone response initially falls on individual curves at the undrained limit (equation (7)), and gradually converges to the corresponding drained limit (equation (11)) as time increases. The backbone curves in Fig. 7 can be estimated by

$$
\frac{H}{W^{\prime}}=\frac{H_{\mathrm{d}}}{W^{\prime}}-\left(\frac{H_{\mathrm{d}}}{W^{\prime}}-\frac{H_{\mathrm{cu}}}{W^{\prime}}\right) 0 \cdot 5^{\left(T_{\mathrm{h}} / T_{\mathrm{h}, 50}\right)^{m_{2}}}
$$

where $T_{\mathrm{h}, 50}$ is the time at which the frictional resistance is midway between the undrained and drained limits. $T_{\mathrm{h}, 50}=0.02$ and $m_{2}=0.65$ provide a good fit to the backbone curves.

\section{Periodic undrained sliding with intervening full primary consolidation}

In this section, periodic undrained sliding with intervening full primary consolidation is considered for a selected vertical load mobilisation, taken as $v_{\mathrm{p}}$ of $0 \cdot 3$. The effect of the vertical load mobilisation and degree of intervening consolidation are discussed in the next section and the analysis procedure is generalised.

The periodic sliding events of the mudmat were carried out at a normalised velocity of $v h_{\mathrm{s}} / c_{\mathrm{v} 0}=10^{3}$ over a distance of $0 \cdot 2 B$, ensuring a fully undrained condition was maintained during sliding. The intervening period of consolidation

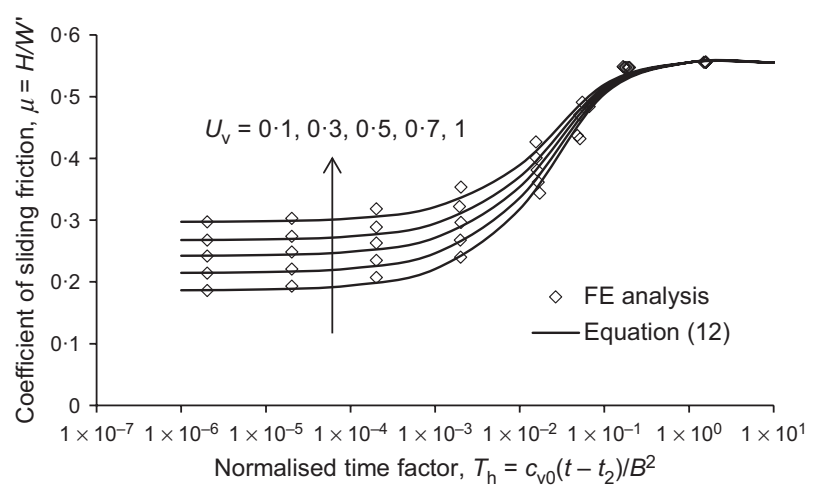

(a)

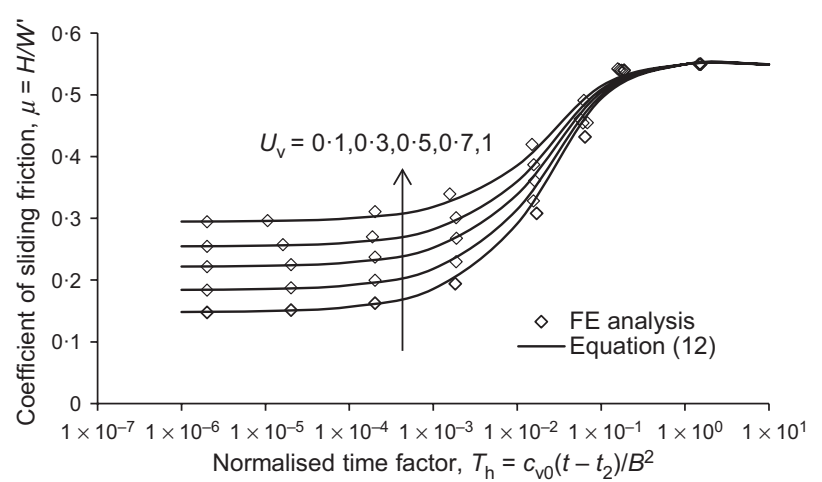

(b)

Fig. 7. Backbone response for undrained continuous sliding for varying operative vertical load and degree of primary consolidation following touchdown: (a) $v_{\mathrm{p}}=0.3$; (b) $v_{\mathrm{p}}=0.5$

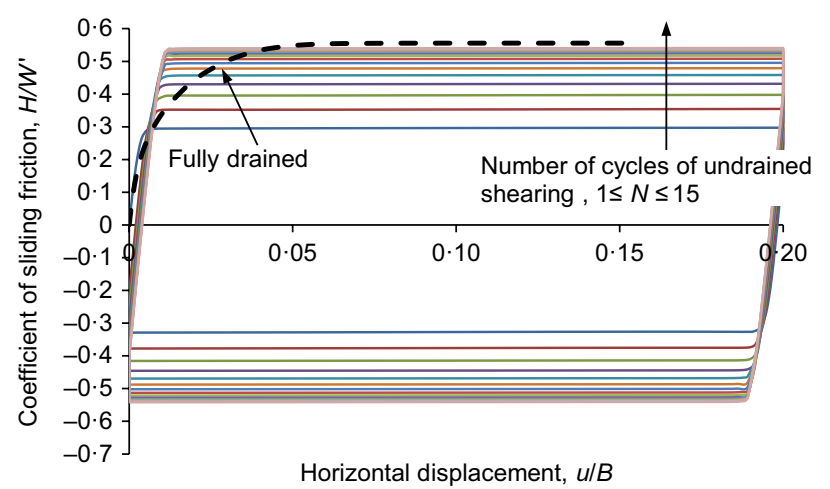

Fig. 8. Evolution of coefficient of frictional sliding $\left(U_{\mathrm{v}}=1 ; U_{\mathrm{i}}=1\right)$

between each forward and reverse slide was sufficient to ensure complete dissipation of excess pore pressure. Fig. 8 shows the coefficient of sliding friction, $\mu=H / W^{\prime}$, with normalised lateral displacement, $u / B$, under periodic undrained sliding with intervening full primary consolidation. The coefficient of sliding friction evolves from the undrained value, equivalent to the in situ undrained strength ratio $R$, and reaches the drained limit, given by equation (11), within 15 episodes.

Figure 9 shows the cycle-by-cycle $e-\ln \sigma_{\mathrm{v}}^{\prime}$ path for a representative soil element beneath the centroid of the mudmat for full primary self-weight consolidation post touchdown, $U_{\mathrm{v}}=1$, and full primary intervening consolidation between slide events, $U_{\mathrm{i}}=1$, where $U_{\mathrm{i}}$ is defined by the timesettlement responses of the mudmat during the intervening periods of reconsolidation. During the initial forward slide of the mudmat ( $B \rightarrow C$ in Fig. 9), the effective vertical stress in 


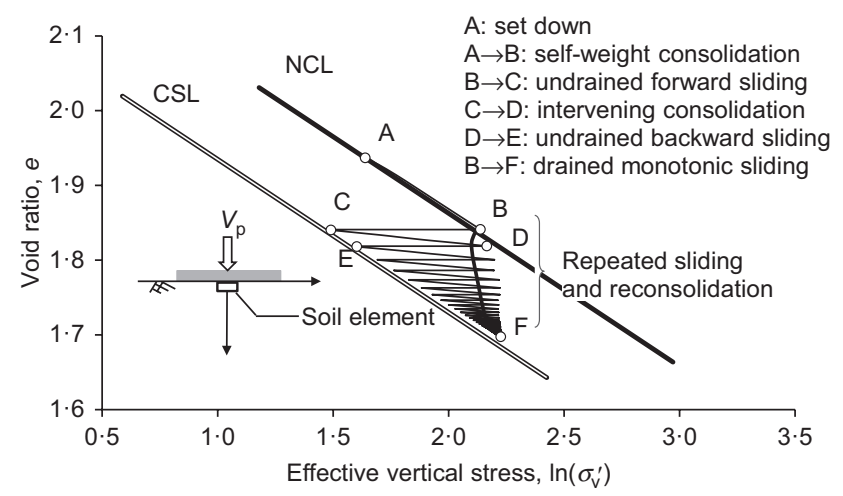

Fig. 9. Stress-volume path of a representative soil element beneath mudmat $\left(U_{v}=1 ; U_{i}=1\right)$

the soil reduces as the stress path moves to the critical state line, CSL. The effective vertical stress then recovers to the initial self-weight value during the intervening reconsolidation $(C \rightarrow D)$, with associated pore pressure dissipation and void ratio reduction. The subsequent slides and intervening periods of reconsolidation result in successive generation and dissipation of excess pore pressure caused by sliding. The process repeats over the lifetime of the mudmat until the soil beneath the mat undergoes sufficient cycles of shearing, pore pressure generation and reconsolidation to reach a final critical void ratio $(\mathrm{F})$, thereby eliminating any tendency for contraction and further excess pore pressure generation.

The rise in lateral sliding resistance resulting from periodic sliding events and intervening consolidation can be captured by an analytical framework (Fig. 10(a)) of a form introduced in White \& Hodder (2010) and extended in White et al. (2015), based on the gain in operative undrained strength that depends on the reduction in the void ratio, $e$, by equation (13), which is a geometric sum of the gain in each cycle.

$$
\frac{\ln s_{\mathrm{u}}-\ln s_{\mathrm{u} i}}{\ln s_{\mathrm{uf}}-\ln s_{\mathrm{u} i}}=\frac{\Delta e}{\Delta e_{\mathrm{f}}}=\frac{\kappa^{\prime}}{\lambda} \sum_{i=1}^{n}\left(1-\frac{\kappa^{\prime}}{\lambda}\right)^{n-1}
$$

where $n$ represents the current number of slides completed and is equal to $2 N$, with $N$ being the current number of episodes comprising two sliding and two reconsolidation events, which is equivalent to the number of operating cycles (i.e. start-up/shut-down cycles). $\kappa^{\prime}$ is the recompression index with respect to effective vertical stress, $\sigma_{\mathrm{v}}^{\prime}$, rather than the mean stress, $p^{\prime}$.

$$
\kappa^{\prime}=\frac{\Delta}{(\lambda-\kappa) \ln \left(3 / 1+2 K_{0}\right)+\Delta} \kappa
$$

where $\Delta$ is the change in void ratio between the CSL and the $K_{0}$ normally consolidated line $\left(K_{0}-\mathrm{NCL}\right)$ at a single effective stress level.

$$
\Delta=e_{N}-e_{\mathrm{cs}}-\ln \left[\left(\frac{3\left(1-K_{0}\right)}{M\left(1+2 K_{0}\right)}\right)^{2}+1\right]
$$

where $e_{N}$ is the void ratio at $p^{\prime}=1 \mathrm{kPa}$ on the virgin compression line, NCL.

The unload-reload gradient $\kappa^{\prime}$ in $e-\ln \sigma_{\mathrm{v}}^{\prime}$ is approximately 0.033 based on the parameters listed in Table 1 . The reduction in void ratio during each reconsolidation event depends on the unload-reload gradient $\kappa^{\prime}$, whereas the final reduction depends on the steepness of the CSL, $\lambda$. The hardening process is therefore also independent of the selected surcharge. The results of the increase in the sliding resistance derived from the FE analysis show good agreement with the
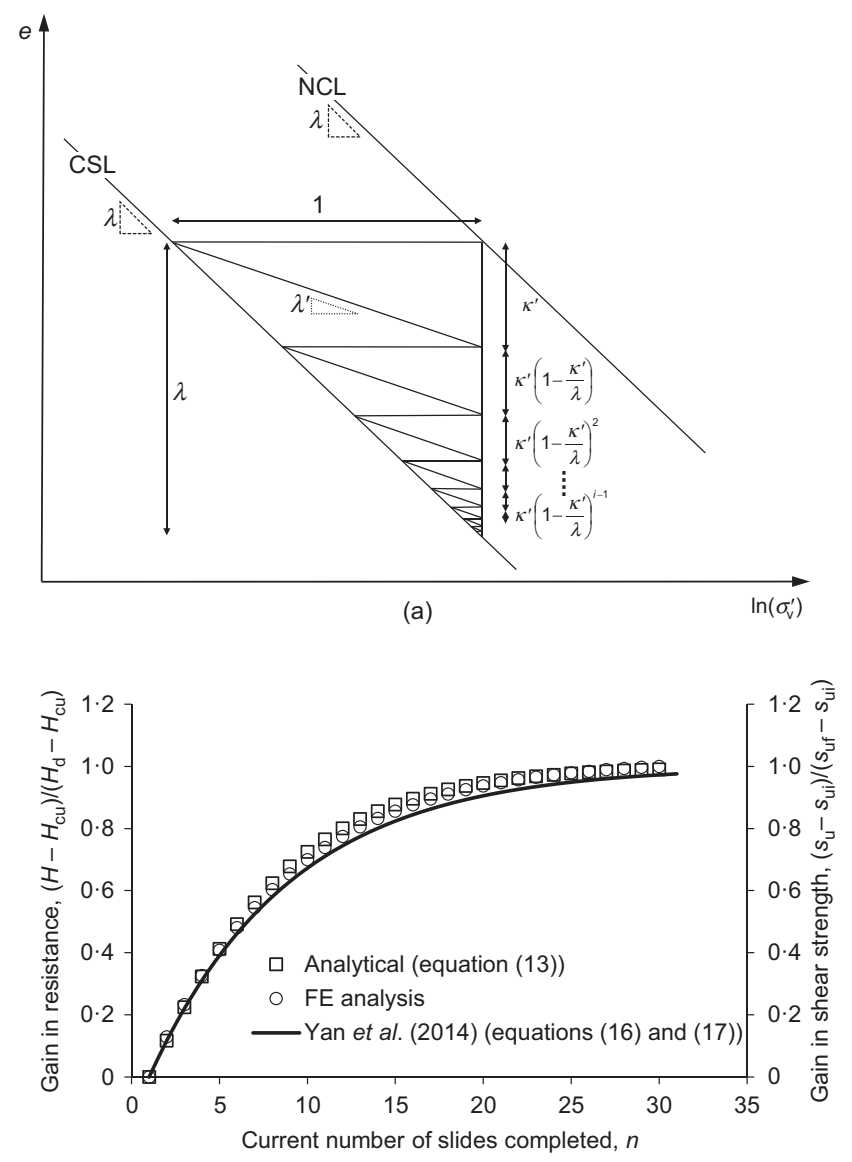

(b)

Fig. 10. Analytical model and power law to predict gain in horizontal resistance ( $\left.U_{\mathrm{v}}=1 ; U_{\mathrm{i}}=1\right)$ : (a) analytical model; (b) power law

analytical solution yielded by equation (13), where the basal sliding mechanism allows $s_{\mathrm{u}}, s_{\mathrm{u} i}$ and $s_{\mathrm{uf}}$, to be taken as being in the same proportions as $H, H_{\mathrm{cu}}$ and $H_{\mathrm{d}}$ (Fig. 10(b)). Alternatively, an exponential relationship proposed by Yan et al. (2014) might be employed for predicting the resistance mobilised during the $n$th slide

$$
\frac{H-H_{\mathrm{cu}}}{H_{\mathrm{d}}-H_{\mathrm{cu}}}=1-0 \cdot 5^{(n-1) / n_{50}}
$$

where $n_{50}$ is the number of cycles of movement and consolidation required to achieve $50 \%$ of the full hardening process for the frictional resistance, depending on the ratio of $\kappa^{\prime} / \lambda$, given by equation (17) as suggested by Yan et al. (2014).

$$
n_{50}=\frac{0 \cdot 9}{\kappa^{\prime} / \lambda}
$$

Figure 11 shows the reduction of the void ratio for the representative soil element beneath the centroid of the mudmat as shown in Fig. 9, due to periodic undrained sliding with intervening full primary reconsolidation for the case of $30 \%$ completion of the self-weight consolidation post touchdown, that is, $U_{\mathrm{v}}=0 \cdot 3,\left(\mathrm{~A} \rightarrow \mathrm{B}^{\prime}\right)$. The only difference is the reduction in the void ratio during reconsolidation $\left(\mathrm{C}^{\prime} \rightarrow \mathrm{B}\right)$ following the first slide $\left(\mathrm{B}^{\prime} \rightarrow \mathrm{C}^{\prime}\right)$, where the residual excess pore pressure due to mudmat touchdown and the newly induced excess pore pressure from undrained shearing have dissipated, with the effective vertical stress recovering to B. The $e-\ln \left(\sigma_{\mathrm{v}}^{\prime}\right)$ path for the following cycle of shearing and reconsolidation generally follows that shown in Fig. 9, for full primary consolidation following touchdown. 


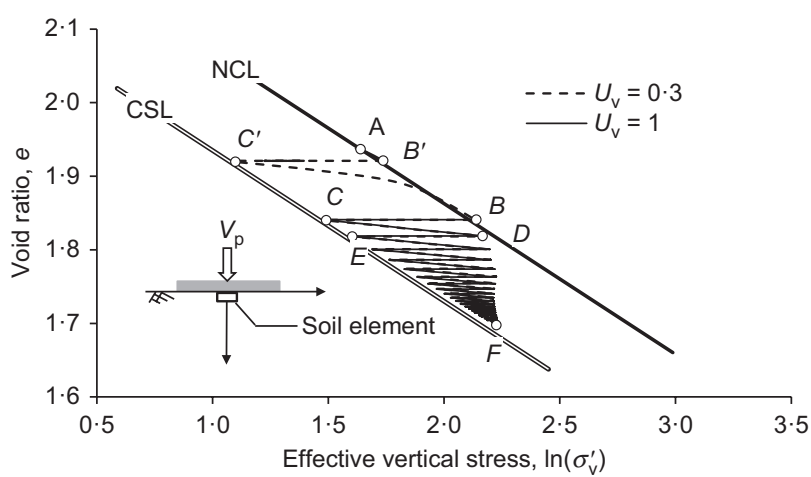

Fig. 11. Comparison of stress-volume path for a soil element for different $U_{\mathrm{v}}$

In contrast to undrained continuous shearing, the rate of hardening for sliding resistance for periodic shearing with intervening full primary consolidation is independent of the degree of the primary consolidation after touchdown, $U_{\mathrm{v}}$, after the first cycle of foundation movement, and reached the drained limit after a cumulative time of $T_{\mathrm{h}} \sim 5$ since the start of pipeline operation. All these cases show a much stiffer response compared with undrained continuous sliding (Fig. 12). The evolution of the horizontal resistance for periodic shearing with intervening full primary consolidation $\left(U_{\mathrm{i}}=1\right)$ can be predicted using equation (12) but with different values of $T_{\mathrm{h}, 50}$ and $m_{2} . T_{\mathrm{h}, 50}=0.7$ and $m_{2}=0.9$ were found to give the best fit for this case.

The increase in the undrained shear strength along the centreline below the mudmat is shown in Fig. 13. The initial soil strength profile was proportional to depth according to equation (1), with a value of $s_{\mathrm{um}}=1.431 \mathrm{kPa}$. After full primary consolidation under the operative vertical load, this mudline strength increased by $60 \%$, to $2.285 \mathrm{kPa}$. A simple estimation of the rise in the strength at mudline level, considering the soil element as indicated in Fig. 9, would be $e^{\left(e_{1}-e_{\mathrm{cs}}\right) / \lambda} \sim 1.9$ due to the periodic shearing and reconsolidation, with $e_{1}$ being the intercept $(\sim 2 \cdot 273)$ on $e-\ln \left(\sigma_{\mathrm{v}}\right)$ at $\sigma_{\mathrm{v}}^{\prime}=1 \mathrm{kPa}$. The zone of strength gain extended approximately $0.3 B$ beneath the mudmat, which is consistent with experimental observations from model tests of mobile foundations (Cocjin et al., 2015).

\section{Periodic undrained sliding with intervening partial consolidation}

The generation and dissipation of excess pore pressure is concurrent for undrained continuous shearing if only partial consolidation has been achieved under the self-weight load $\left(U_{\mathrm{v}}<1\right)$, whereas no residual excess pore pressure exists in the subsoil at the start of each individual slide for the case of undrained periodic sliding with intervening full primary consolidation $\left(U_{\mathrm{i}}=1\right)$. In the field, the time lag between slide events of a mobile mudmat will be determined by the operation schedule of the attached pipelines. Table 3 summarises various intervening periods of reconsolidation for a mobile mudmat associated with different schedules of pipeline start-up and shut-down, with a constant degree of consolidation between mudmat touchdown and the start of pipeline operation $\left(U_{\mathrm{v}}=0.5\right)$. The rate of hardening for sliding resistance for the example cases is plotted in Fig. 14, along with the hardening responses for undrained continuous shearing, and for periodic shearing with full intervening primary consolidation. Fig. 14 shows that the hardening responses for all the periodic shearing and reconsolidation cases are bracketed by that for undrained continuous

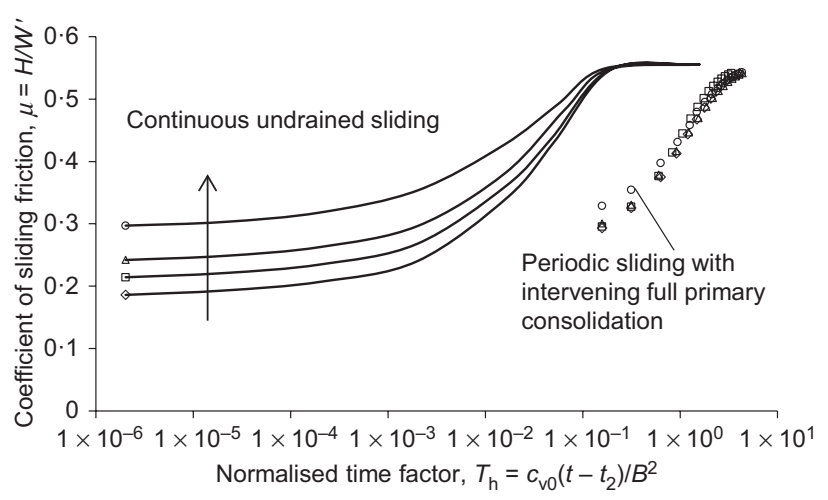

Fig. 12. Hardening process of sliding resistance for periodic shearing

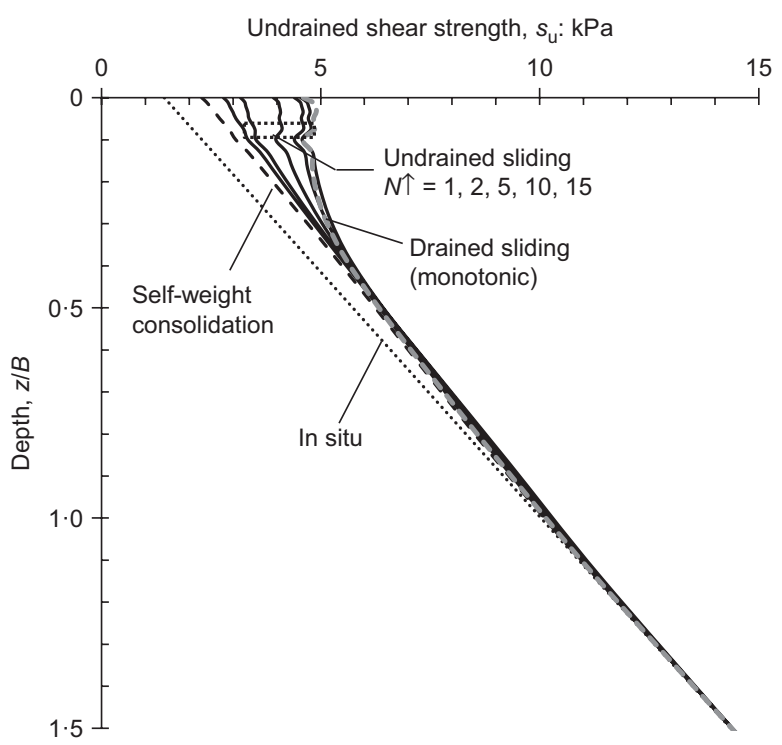

Fig. 13. Profile of soil undrained shear strength during the episodic foundation sliding $\left(U_{\mathrm{v}}=1 ; U_{\mathrm{i}}=1\right)$

Table 3. Matrix of prescribed operating conditions for mudmats

\begin{tabular}{l|l|l|l}
\hline $\begin{array}{l}\text { Case } \\
\text { number }\end{array}$ & $\begin{array}{l}\text { Degree of } \\
\text { primary } \\
\text { consolidation } \\
\text { under } \\
\text { self-weight, } U_{\mathrm{v}}\end{array}$ & $\begin{array}{l}\text { Intervening periods of rest } \\
\text { Following } \\
\text { forward slide } \\
\text { (start-up), } t_{\text {op }}\end{array}$ & $\begin{array}{l}\text { Following } \\
\text { backward slide } \\
\text { (shut-down), } t_{\text {sd }}\end{array}$ \\
\hline 1 & & $\begin{array}{l}0 \cdot 25 \text { years } \\
1.5 \text { years } \\
1.5 \text { years } \\
5 \text { years } \\
10 \text { years }\end{array}$ & $\begin{array}{l}1 \text { day } \\
1 \text { day } \\
7\end{array}$ \\
4 & $0 \cdot 5$ & $\begin{array}{l}7 \text { days } \\
7 \text { days }\end{array}$ \\
5 & & &
\end{tabular}

shearing and periodic shearing with intervening full primary consolidation.

For the hypothetical cases considered, a reconsolidation period of $t_{\mathrm{op}}=3$ months $\left(0.25\right.$ years, $T_{\mathrm{op}}=t_{\mathrm{op}} c_{\mathrm{vo}} / B^{2}$ $\left.\sim 2.23 \times 10^{-3}\right)$ and $t_{\mathrm{op}}=1.5$ years $\left(T_{\mathrm{op}} \sim 1.34 \times 10^{-2}\right)$ immediately after the forward slide (i.e. pipeline start up) were respectively prescribed for case 1 and case 2, representing different periods for pipeline operation. The subsequent waiting period between the backward slide and the next forward slide (i.e. pipeline shut-down period), $t_{\mathrm{sd}}$, was adopted as 1 day for both cases $\left(T_{\mathrm{sd}}=t_{\mathrm{sd}} c_{\mathrm{v} 0} / B^{2}\right.$ $\sim 2 \cdot 48 \times 10^{-5}$ ) to reflect field conditions. In case 3 , the 


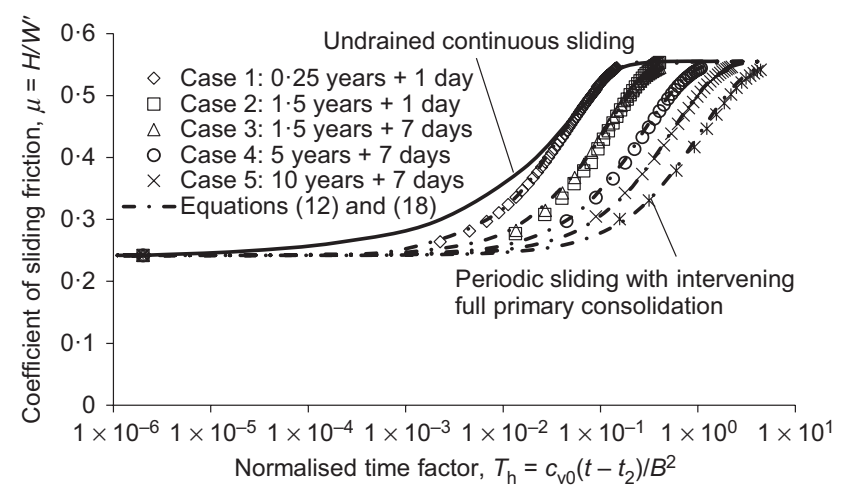

Fig. 14. Responses of a mobile mudmat under periodic shearing with partial intervening consolidation $\left(U_{\mathrm{v}}=0 \cdot 5\right)$

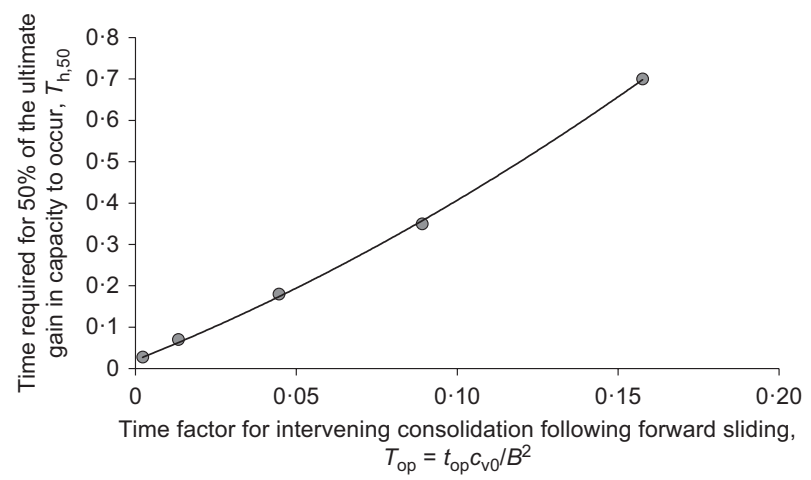

Fig. 15. Evolution of $T_{\mathrm{h}, 50}$ with varying $T_{\mathrm{op}}$

period for pipeline operation was identical with case 2 , but a 7 -day period $\left(T_{\text {sd }} \sim 1.73 \times 10^{-4}\right)$ was prescribed for pipeline shut-down. The hardening response of case 1 initially falls outside the backbone response for undrained continuous shearing before converging with the backbone curve with time. The hardening processes in case 2 and case 3 overlap, indicating the independence of the hardening response from the relatively short shut-down period, $t_{\mathrm{sd}}$. The curves for the hardening process for all of the five cases offset gradually towards that for the case of periodic shearing, with full primary reconsolidation between slides with increasing intervening period of rest following the forward slide, $t_{\mathrm{op}}$.

To predict the hardening process, equation (12) is again adopted with $m_{2}$ maintained constant as 0.9 , since all the curves are approximately parallel. The only variable for each case is the required time for achieving the midway of the corresponding undrained and drained limits of the horizontal resistance, $T_{\mathrm{h}, 50}$. The estimated values of $T_{\mathrm{h}, 50}$ for periodic shearing are presented in Fig. 15 as a quadratic polynomial function of the equivalent time factor for the intervening consolidation period following the forward slide, $t_{\mathrm{op}}$.

$$
T_{\mathrm{h}, 50}=7 \cdot 5505 T_{\mathrm{op}}^{2}+3 \cdot 1136 T_{\mathrm{op}}+0.02
$$

$t_{\mathrm{op}}$ represents the meaningful consolidation, which in practice takes place in operation with negligible consolidation during the limited duration of shut downs.

Equations (12) and (18) are independent of the vertical load mobilisation $v_{\mathrm{p}}$ due to selected relative self-weight, and the degree of consolidation $U_{\mathrm{v}}$ following mudmat touchdown. Predictions of the hardening process for horizontal resistance for $v_{\mathrm{p}}=0.3$ and 0.5 , and $U_{\mathrm{v}}=0.3$ derived from $\mathrm{FE}$ analyses are shown in Figs 16(a) and 16(b) compared with predictions from equations (12) and (18).

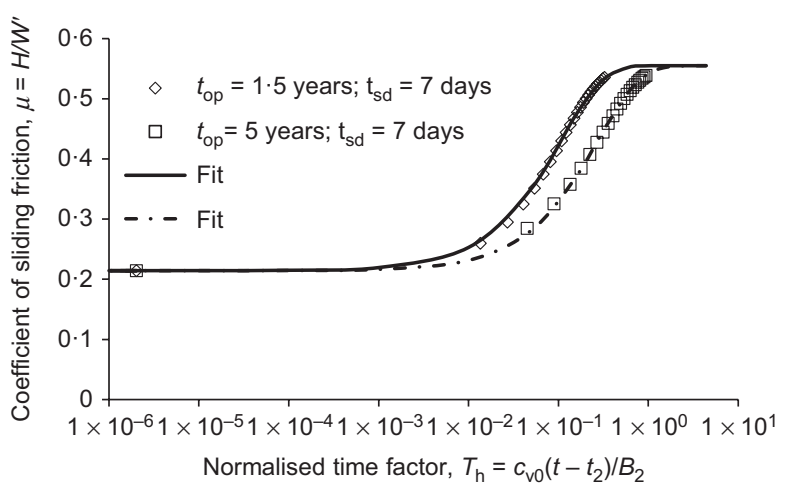

(a)

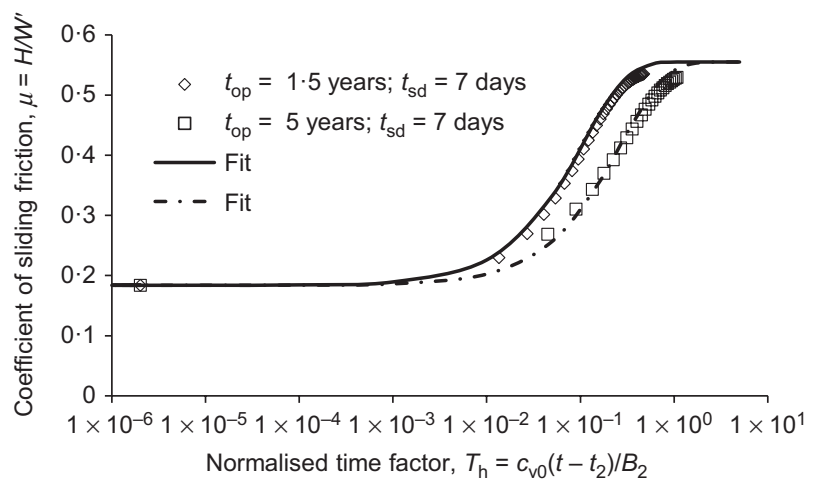

(b)

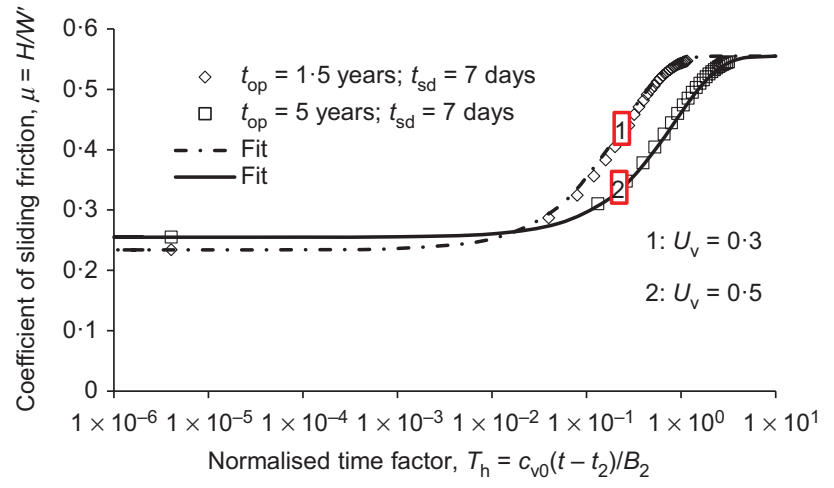

(c)

Fig. 16. Effect of self-weight load, degree of primary consolidation and overburden stress on the hardening process: (a) $v_{\mathrm{p}}=0 \cdot 3, U_{\mathrm{v}}=0.3$, $\sigma_{\mathrm{vo}}=5 \mathrm{kPa}$; (b) $v_{\mathrm{p}}=0.5, U_{\mathrm{v}}=0.3, \sigma_{\mathrm{vo}}=5 \mathrm{kPa}$; (c) $v_{\mathrm{p}}=0.3$, $\sigma_{\mathrm{vo}}=16 \mathrm{kPa}$

Sensitivity of the gain in sliding resistance due to intervening partial consolidation on the selected surcharge was also examined. The FE results for a different surcharge of $\sigma_{\mathrm{vo}}=16 \mathrm{kPa}$ in comparison with the base case value $\sigma_{\mathrm{vo}}=5 \mathrm{kPa}$ are well predicted by the equations (12) and (18), indicating that the gain in sliding resistance due to intervening partial consolidation is insensitive to the surcharge (Fig. 16(c)).

The procedure set out above enables prediction of the evolution of gain in horizontal resistance of a tolerably mobile mudmat under periodic sliding and intervening consolidation by scaling the hardening response for continuous undrained shearing by an amount depending on the degree of intervening consolidation between sliding events. The equations presented in this paper are relevant for the case of uniform periods of reconsolidation (of any degree) between each sliding event. The method can be modified to nonuniform periods of reconsolidation between sliding events by adopting a cycle-by-cycle approach using the analytical 
solution (Fig. 10(a)), similar to that described by White et al. (2015) for prediction of pipeline walking.

\section{Summary of procedure}

Sliding resistance of a tolerably mobile mudmat under periodic shearing and reconsolidation resting on a normally consolidated soil can be predicted with the following procedure.

(a) Assess the unconsolidated undrained uniaxial capacity, $V_{\mathrm{uu}}$, and vertical load mobilisation, $v_{\mathrm{p}}=V_{\mathrm{p}} / V_{\mathrm{uu}}$, for a given mudmat geometry, self-weight and in situ soil shear strength profile.

(b) Calculate the time factor, $T_{\mathrm{v}}$ (equation (3)), for a given time delay between mudmat touchdown and start-up of pipeline operation, based on the in situ coefficient of consolidation, $c_{\mathrm{v} 0}$ (equation (4)). Determine the degree of consolidation $U_{\mathrm{v}}$ using the time factor $T_{\mathrm{v}}$ (equation (5)).

(c) Evaluate the fully undrained horizontal resistance $H_{\mathrm{cu}}$ using equations (7) and (8), and the fully drained horizontal resistance $H_{\mathrm{d}}$ through equations (9) and (11).

(d) For a given intervening period of reconsolidation following the forward slide, $t_{\mathrm{op}}$, estimate $T_{\mathrm{h}, 50}$ (for the hardening process to achieve midway between $H_{\mathrm{cu}}$ and $H_{\mathrm{d}}$ ) through equation (18).

(e) Predict the hardening process giving the evolution of horizontal resistance using equation (12).

\section{CONCLUSIONS}

The sliding resistance of a tolerably mobile subsea mudmat under periodic shearing and reconsolidation was investigated by FE analyses. The gain in sliding resistance, or the 'hardening response', under periodic sliding with intervening consolidation has been shown to be bounded by the hardening response under undrained continuous shearing with concurrent consolidation, and periodic shearing with full primary consolidation between cycles. The hardening response for periodic shearing with intervening partial consolidation has been shown to be predicted by scaling the hardening response for undrained continuous sliding by an amount depending on the intervening period of reconsolidation during pipeline operation. The number of cycles of shearing and reconsolidation to reach the drained limit is governed by the ratio of $\kappa^{\prime} / \lambda$ and the degree of consolidation permitted between sliding events. Expressions and an analysis procedure are provided for predicting the hardening response of horizontal sliding resistance for tolerably mobile subsea mudmats on soft clay. The procedure has been proven general and applicable to MCC parameters and overburden stress other than those selected in this study.

\section{ACKNOWLEDGEMENTS}

This work forms part of the activities of the Centre for Offshore Foundation Systems (COFS), established in 1997 under the Australian Research Council's Special Research Centres Program, and supported as a node of the Australian Research Council's Centre of Excellence for Geotechnical Science and Engineering, and through the Fugro Chair in Geotechnics, the Lloyd's Register Foundation Chair and Centre of Excellence in Offshore Foundations and the Shell EMI Chair in Offshore Engineering. The first author is supported by the Lloyd's Register Foundation and ARC grant DP140100684. Lloyd's Register Foundation helps to protect life and property by supporting engineering-related education, public engagement and the application of research. The second author is supported through ARC grant CE110001009. The work presented in this paper is supported through ARC grant DP140100684. This support is gratefully acknowledged.

\section{NOTATION}

$A$ bearing area of mudmat

$A_{i}$ contact area of $i$ th element

$B$ mudmat breadth

$c_{\mathrm{v} 0}$ in situ coefficient of consolidation

$e_{0}$ initial void ratio

$e_{\mathrm{cs}}$ void ratio at $p^{\prime}=1 \mathrm{kPa}$ on critical state line

$f_{\text {su }}$ shear strength factor

$f_{\sigma}$ stress factor

$H_{\mathrm{cu}}$ consolidated undrained horizontal resistance

$H_{\text {cu, max }}$ maximum consolidated undrained horizontal resistance corresponding to fully primary consolidation following touchdown

$H_{\text {uu }}$ unconsolidated undrained horizontal resistance

$H_{\mathrm{uu}}^{*} \quad$ unconsolidated undrained horizontal resistance accounting for $v_{\mathrm{p}}=V_{\mathrm{p}} / V_{\mathrm{uu}}$

$h_{\mathrm{s}}$ thickness of shear band

$j$ number of elements across the soil-foundation interface

$K_{0}$ coefficient of earth pressure at rest

$k$ soil permeability

$L$ mudmat length

$N$ current number of episodes comprising two sliding and two reconsolidation events, which is equivalent to the number of operating cycles (i.e. start-up/shut-down cycles)

$N_{\mathrm{cV}}$ unconsolidated undrained vertical bearing capacity factor

$n$ current number of slides completed

$p^{\prime}$ mean effective stress

$q_{\mathrm{f}}$ shear stress in the deviatoric plane at failure condition

$R$ normally consolidated undrained shear strength ratio, $R=s_{\mathrm{u}} / \sigma_{\mathrm{v}}^{\prime}$

$s_{\mathrm{uf}} \quad$ undrained shear strength at critical state

$s_{\mathrm{u} i}$ in situ undrained shear strength

$s_{\mathrm{um}} \quad$ undrained strength at mudline level

$T_{\mathrm{h}}$ time factor for the elapsed time since the start of pipeline operation

$T_{\mathrm{h}, 50}$ time factor at which the frictional resistance is midway between the undrained and drained limits

$T_{\mathrm{op}} \quad$ time factor for pipeline operation

$T_{\mathrm{v}}$ time factor for the elapsed time since touchdown

$T_{\mathrm{v}, 50}$ time factor corresponding to $50 \%$ consolidation settlement since touchdown

$t$ time

$t_{\mathrm{op}}$ period of pipeline operation

$t_{\mathrm{sd}} \quad$ pipeline shut-down period

$t_{1}$ time at mudmat touchdown

$t_{2}$ time at the start of pipeline operation

$U_{\mathrm{i}} \quad$ degree of intervening consolidation

$U_{\mathrm{v}}$ degree of consolidation following touchdown

$V_{\mathrm{p}} \quad$ vertical self-weight load

$V_{\text {uu }}$ unconsolidated, undrained vertical capacity

$v$ velocity of mudmat sliding

$v_{\mathrm{p}}$ vertical load mobilisation, $v_{\mathrm{p}}=V_{\mathrm{p}} / V_{\mathrm{uu}}$

$W^{\prime} \quad$ submerged unit weight of mudmat

$w$ consolidation settlement following touchdown

$w_{\mathrm{f}}$ consolidation settlement corresponding to full primary consolidation following touchdown

$\gamma^{\prime}$ effective unit weight of soil

$\gamma_{\mathrm{w}}$ unit weight of pore water

$\Delta \quad$ change in void ratio between critical state line and $K_{0}$ normally consolidated line

$\Theta \quad$ Lode's angle

$\kappa$ recompression index in $e-\ln p^{\prime}$

$\kappa^{\prime} \quad$ recompression index in $e-\ln \sigma_{\mathrm{v}}^{\prime}$

$\lambda$ virgin compression index

$\mu$ coefficient of sliding friction

$v^{\prime}$ Poisson ratio

$\rho$ undrained shear strength gradient

$\sigma_{\mathrm{v}}^{\prime} \quad$ vertical effective stress

$\sigma_{\mathrm{vo}}$ surcharge 
$\sigma_{z \mathrm{f}}^{\prime} \quad$ normal stress in $z$ direction at failure

$\tau_{z x f} \quad$ shear stress in the $x o z$ plane at failure

$\phi_{\mathrm{cs}}^{\prime} \quad$ critical state angle of shearing resistance

$\phi_{\mathrm{tc}}^{\prime} \quad$ friction angle for triaxial compression

\section{REFERENCES}

API (American Petroleum Institute) (2011). RP 2GEO geotechnical and foundation design considerations, 1st edn. Washington, DC, USA: American Petroleum Institute.

Bretelle, S. \& Wallerand, R. (2013). Fondations superficielles glissantes pour l'offshore profond - methodologie de dimensionnement. In Proceedings of the 18th international conference on soil mechanics and geotechtechnical engineering (ICSMGE), Paris, France (eds P. Delage, J. Descrues, R. Frank, A. Peuch and F. Schlosser), pp. 2331-2334. Paris, France: Presses de Ponts (in French).

Cathie, D., Morgan, N. \& Jaeck, C. (2008). Design of sliding foundations for subsea structures. In BGA international conference on foundations, Dundee, UK (ed. M. J. Brown), pp. 24-27. Bracknell, UK: IHS BRE Press.

Cocjin, M., Gourvenec, S., White, D. \& Randolph, M. F. (2014). Tolerably mobile subsea foundations: Observations of performance. Géotechnique 64, No. 11, 809-895, http://dx.doi. org/10.1680/geot.14.P.098.

Cocjin, M., Gourvenec, S., White, D. \& Randolph, M. (2015). Effects of drainage on the response of a sliding subsea foundation. In Proceedings of the 3rd international symposium on frontiers in offshore geotechnics (ISFOG 2015), Oslo, Norway (ed. V. Meyer), pp. 777-782. London, UK: CRC Press.

Dassault Systèmes (2010). Abaqus analysis users' manual. Providence, RI, USA: Simulia Corp.

Deeks, A., Zhou, H., Krisdani, H., Bransby, F. \& Waston, P. (2014). Design of direct on-seabed sliding foundations. In Proceedings of the 33rd international conference on ocean, offshore and arctic engineering (OMAE 2014), San Francisco, USA, vol. 3, paper OMAE2014-24393. New York, NY, USA: American Society of Mechanical Engineers.

Feng, X. \& Gourvenec, S. (2015). Consolidated undrained loadcarrying capacities of mudmats under combined loading in six degrees-of-freedom. Géotechnique 65, No. 7, 563-575, http://dx.doi.org/10.1680/geot.14-P-090.

Feng, X., Randolph, M. F., Gourvenec, S. \& Wallerand, R. (2014). Design approach for rectangular mudmats under fully threedimensional loading. Géotechnique 64, No. 1, 51-63, http://dx. doi.org/10.1680/geot.13.P.051.

Gourvenec, S., Vulpe, C. \& Murthy, T. (2014). A method for predicting the consolidated undrained bearing capacity of shallow foundation. Géotechnique 64, No. 3, 215-225, http://dx.doi.org/ 10.1680/geot.13.P.101.

ISO (International Standards Organisation) (2003). ISO19901-4: petroleum and natural gas industries specific requirements for offshore structures - part 4: geotechnical and foundation design considerations, 1st edn. Geneva, Switzerland: International Standards Organisation.

Potts, D. M. \& Zdravkovic, L. (1999). Finite element analysis in geotechnical engineering - theory. London, UK: Thomas Telford.

Randolph, M. F., Gaudin, C., Gourvenec, S. M., White, D. J., Boylan, N. \& Cassidy, M. J. (2011). Recent advances in offshore geotechnics for deep water oil and gas developments. Ocean Engng 38, No. 7, 818-834.

Randolph, M. F., White, D. J. \& Yan, Y. (2012). Modelling the axial soil resistance on deep-water pipelines. Géotechnique 62, No. 9, 837-846, http://dx.doi.org/10.1680/geot.12.OG.010.

Roscoe, K. H. \& Burland, J. B. (1968). On the generalized stressstrain behaviour of wet clay. In Engineering plasticity (eds J. Heymen and F. Leckie), pp. 535-609. Cambridge, UK: Cambridge University Press.

Stewart, D. P. (1992). Lateral loading of piled bridge abutments due to embankment construction. PhD thesis, The University of Western Australia, Perth, Australia.

Stuyts, B., Wallerand, R. \& Brown, B. (2015). A framework for design of sliding mudmat foundations. In Proceedings of the $3 r$ international symposium on frontiers in offshore geotechnics (ISFOG 2015), Oslo, Norway (ed. V. Meyer), pp. 807-812. London, UK: CRC Press.

Vermeer, P. A. \& Verruijt, A. (1981). An accuracy condition for consolidation by finite elements. Int. J. Numer. Analyt. Methods Geomech. 5, No. 1, 1-14.

White, D. J. \& Hodder, M. (2010). A simple model for the effect on soil strength of episodes of remoulding and reconsolidation. Can. Geotech. J. 47, No. 7, 821-826, http://dx.doi.org/10.1139/ T09-137.

White, D. J., Westgate, A., Ballard, J. C., de Brier, C. \& Bransby, M. F. (2015). Best practice geotechnical characterization and pipe-soil interaction analysis for HPHT pipeline design. Proceedings of the offshore technology conference, Houston, TX, paper OTC-26026-MS.

Yan, Y., White, D. J. \& Randolph, M. F. (2014). Cyclic consolidation and axial friction for seabed pipelines. Géotechnique Lett. 4, No. 3, 165-169, http://dx.doi.org/10.1680/geolett.14.00032.

Zhou, H., Krisdani, H., Maujean, R. \& Deeks, A. D. (2015). System investigation of direct on-seabed sliding foundations. In Proceedings of the 3rd international symposium on frontiers in offshore geotechnics (ISFOG 2015), Oslo, Norway (ed. V. Meyer), pp. 825-830. London, UK: CRC Press. 